\title{
AS CONTRIBUIÇÕES DO MELHORAMENTO GENÉTICO DE PLANTAS PARA A PRODUÇÃO ALIMENTÍCIA: ASPECTOS ECONÔMICOS E SUSTENTÁVEIS
}

\author{
Talles de Oliveira Santos ${ }^{1}$ \\ Luan Ítalo Rebouças Rocha
}

Resumo: O grande crescimento populacional no Brasil e no mundo exige a todo momento o aumento das cadeias produtivas de alimento para que as necessidades da população sejam supridas. Porém é preciso que esse aumento nas cadeias produtivas seja realizado de maneira sustentável uma vez que a fragmentação da vegetação natural dos biomas é um problema crescente no Brasil. Logo, é preciso que sejam utilizadas alternativas para uma produção que não explore demasiadamente os recursos naturais. Tendo isso em vista, esse trabalho, baseado em uma revisão de literatura, tem como objetivo destacar a relevância do melhoramento para o Brasil. A importância do melhoramento de plantas é apresentada em diversos estudos realizados, uma vez que a mesma é capaz de aumentar a produtividade das áreas já utilizadas para a agricultura sem a necessidade expansão dessas áreas. Outra vantagem significativa encontrada é no setor econômico, considerando que o Brasil é um dos países que mais produz grãos no mundo. Então, pôde-se perceber o quanto é essencial o desenvolvimento do estudo do melhoramento genético de plantas.

Palavras-chave: Cultivares; Genética; Melhoristas.

\footnotetext{
${ }^{1}$ Curso de Licenciatura em Ciências Biológicas/Instituto Federal do Espírito Santo - Campus de Alegre, Brasil. E-mail: tallesdeoliveira@live.com.

2 Curso de Licenciatura em Ciências Biológicas/Instituto Federal do Espírito Santo - Campus de Alegre, Brasil. E-mail: luanitalo@hotmail.com.
} 